

Annals of DAAAM for 2011 \& Proceedings of the 22nd International DAAAM Symposium, Volume 22, No. 1, ISSN 1726-9679 ISBN 978-3-901509-83-4, Editor B. Katalinic, Published by DAAAM International, Vienna, Austria, EU, 2011 Make Harmony between Technology and Nature, and Your Mind will Fly Free as a Bird Annals \& Proceedings of DAAAM International 2011

\title{
ASPECTS OF THE PRODUCTION CONTROL SYSTEM CONWIP IN SMALL AND MEDIUM SIZED INDUSTRIAL COMPANIES
}

\author{
GASTERMANN, B[ernd] C[hristian]; STOPPER, M[arkus] \& KATALINIC, B[ranko]
}

\begin{abstract}
To achieve their goals in our globalized world full of competition pressure, manufacturing companies will have to adopt production control systems that fit their situation the best. Many approaches exist, each having different properties in different environments. In this paper, an overview of some very common and significant production strategies and systems is provided. The focus here, however, is on non-electronic systems, in particular "constant work-in-process" (CONWIP). The paper outlines various aspects of CONWIP compared to other established production concepts, especially in regard to small and medium-sized manufacturing companies.

Key words: CONWIP, lean management, make-to-order, supply chain management, WIP parameter
\end{abstract}

\section{INTRODUCTION}

When looking at manufacturing companies of various sizes, globalization brought challenges, risks, and opportunities alike. This continuously evolving economic environment leads to shorter product life cycles, diversified and changing customer demands, higher awareness of quality and rapid advancement of manufacturing technology. In order to deal with these new conditions as well as increasing global competition pressure, manufacturing companies around the world began to adopt various manufacturing techniques and technologies that would lead to an improvement of flexibility, product quality and production costs. This endeavor for improvement has become a continuous and essential process. In particular effective production control systems are required. According to Spearman et al. (1990), such systems "produce the right parts, at the right time, at a competitive cost". This often requires actions to reduce, among others, inventory, lead time, waste, and machine failures.

Over the next sections, this paper will introduce some popular manufacturing control strategies and systems, and will eventually discuss the application of "constant work-inprocess" (CONWIP) in small and medium-sized companies.

\section{PRODUCTION STRATEGIES AND SYSTEMS}

Being an important part of supply chain management, there are generally two kinds of production strategies: "pull” and "push". The use of these terms in conjunction with production control systems is very popular although no generally accepted definitions exist (Spearman et al., 1990).

Production systems that release work orders based on a master production schedule (MPS) are classified as push systems. In this case, production is not based on actual customer demand but on forecast demand instead. Subsequently, schedules are generated, which define the release of new production work. Once a new work order has been released it is being processed at each step of the production line until it ends at the finished goods inventory. From there on, those goods are offered to the customer. This means that products are fully produced in advance and sold as products that are not customer-specific, thus anonymous (Jodlbauer, 2008). During the manufacturing process of push systems, internal states like capacities or work-in-process (WIP) are not considered and do not affect the release of new work orders, so information only flows downstream through the manufacturing chain. Hence, push systems are also inherently declared as "make-to-stock" (MTS) (see figure 1).

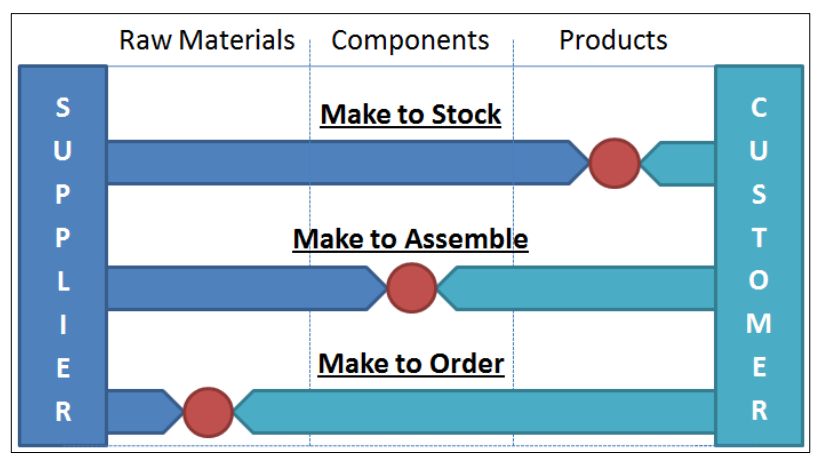

Fig. 1. Three different production approaches and their related order penetration points (OPPs).

Pull systems, on the other hand, are production systems that authorize the release of new work orders based on real demand. The need for products could either be actual customer demand or internal demand from downstream manufacturing stages. Production of certain products only starts once a specific customer order has been received. Dependence on actual demand inherently categorizes these systems as "make-toorder" (MTO) (see figure 1). Authorization signals and information required in this approach flow upstream only, as each manufacturing step declares demand on certain goods from its precedent manufacturing stage.

Based upon these two principles, various electronic and non-electronic production control system implementations exist. Manufacturing companies should try to adopt the one system that fits their individual situations the most. In the following sub-sections, some fundamental computer-assisted and manual production control systems are introduced.

\subsection{MRP and MRP II}

The very popular "material requirements planning" (MRP) system is a production planning and inventory control system, which basically is a push system that could be used for all kinds of production tasks. It plans manufacturing activities, delivering schedules and purchasing activities. Furthermore, MRP ensures that materials are available for production, but also ensures that finished products are available for delivery to customers. The problem with MRP is the integrity of data: If there are errors in any of the relevant input data, then output provided by MRP will also be incorrect. Another problem is the fact that fixed lead times have to be specified, which will be assumed to be the same for each product, no matter how many items have to be produced or what other concurrent items are being made at that 
time (Spearman et al., 1990). This may usually lead to a rather pessimistic specification of lead times, resulting in high WIP and inventory levels. Also, MRP does not take capacity into account, which could lead to implementation problems if there are internal or external capacity constraints.

However, "manufacturing resources planning" (MRP II) largely deals with that problem. It is the successor of MRP and acts as an extension that is used for effective planning of all resources of a manufacturing company, including human resources. MRP II addresses operational planning in units, financial planning and has a simulation capability to answer "what-if" questions. In contrast to its predecessor, it can use both finite and infinite capacity planning. Even fluctuations in forecast data are taken into account.

\subsection{Kanban}

The concept of Kanban is tightly related to lean manufacturing (LM) and just-in-time (JIT) production. Kanban, generally, is a non-electronic pull type production control and scheduling system. It utilizes authorization cards (kanbans) that help to create a demand-driven system by signaling depletion of components or products between two workstations of the production chain. When this signal is received, a process to replenish the goods at that workstation is triggered. Using a fixed amount of cards, WIP at each manufacturing stage is tightly controlled and limited to the total amount of cards in the card set used between two workstations (Marek et al., 2001). Individual card sets are used at different workstations, thus creating individual demand at each precedent workstation.

\subsection{Constant Work-In-Process}

The basic notion of "constant work-in-process" (CONWIP) is to ensure a constant level of WIP throughout the whole production. Spearman et al. (1990) presented CONWIP, which is still quite unknown in Europe, as an enhanced and generalized form of Kanban. Compared to Kanban, however, it is not a pure pull system, but incorporates aspects of both push and pull (Jodlbauer, 2008). While Kanban uses individual card sets between each pair of workstations, only a single global set of cards is used for the whole production process in CONWIP. CONWIP generally is a list-based pull system where demand triggers the release of work orders. Each of these orders is then assigned a global authorization card that remains associated to this specific work order until production is complete. When the product leaves the production system, the card is released, which allows a new work order to enter the production system. Using this approach, WIP is not controlled for each production step but for the whole production system. WIP remains constant (thus the name of CONWIP) as the total amount of cards is also fixed. If a bottleneck occurs, CONWIP allows for reduction of the total number of cards. On the contrary, it also allows increasing the number of cards to elevate WIP and to ensure a higher throughput (Marek et al., 2001).

\section{HYBRID PRODUCTION STRATEGIES}

For many manufacturing companies it is not appropriate to adopt either the MTS or the MTO production approach. But push and pull systems are not mutually exclusive (Spearman et al., 1990), so it is possible to combine both systems into a hybrid production line. Such hybrid systems are often also referred to as "make-to-assemble" (MTA) (see figure 1). MTA is a production strategy where basic components of a product are produced and stocked based on forecast demands. Up to this point, all parts are produced anonymously, that is, without a specific customer order (Jodlbauer, 2008). However, as soon as a customer order is placed, these stocked components are then used to assemble the final product. Looking at this process, the inventory of components clearly is the point that splits the production chain into MTS and MTO. This point of transition from MTS to MTO is called the "order penetration point" (OPP) (Olhager, 2003). The position of this point varies between manufacturing companies, dependent on which approach they have decided to adopt. It is important to wisely choose its location in order to gain benefits from both push and pull strategy. Moving the OPP closer to the customer, for example, improves responsiveness, while moving it farther away from the customer improves flexibility. Having the right balance, a hybrid approach allows for higher order customization and flexibility as well as smaller lead times when compared to traditional MTS or MTO (Olhager, 2003).

\section{CONCLUSION}

So far, an overview of the most important production strategies has been provided and some basic differences between CONWIP and other manufacturing systems have been outlined. As the focus is with small and medium-sized manufacturing companies, the paper will now discuss some aspects of CONWIP in regard to these businesses.

In general, CONWIP is suitable for a wide variety of production environments but it has many advantages that may be particularly important for small and medium-sized companies. Small firms usually have limited manufacturing capacities and capabilities. Therefore, implementation of sophisticated production planning systems is not always appropriate. Sometimes a company lacks the required resources to implement, handle or maintain such systems. In this respect, CONWIP is quite a simple approach as it is based on a basic list of orders and could easily be implemented. When compared to Kanban, for example, CONWIP systems are easier to manage because there is only one set of cards that has to be adjusted (Marek et al., 2001). Furthermore, flow times of CONWIP systems are easily predictable due to constant WIP levels (Spearman et al., 1990). CONWIP allows MTO production even when many variants and materials are used. For smaller companies, it sometimes could also be required to use priorities for work orders based customer importance, which is also supported by CONWIP.

According to Enns \& Rogers (2008), however, it is hard to compare the actual performance of CONWIP with that of other systems. It was found that different studies came to varying conclusions. It is the subject of a subsequent paper to cover the implementation of CONWIP in a concrete small or mediumsized manufacturing company and benchmark its performance.

\section{REFERENCES}

Enns, S.T. \& Rogers, P. (2008). Clarifying CONWIP versus Push System Behavior using Simulation, Proceedings of the 2008 Winter Simulation Conference, Miami, FL, USA, ISBN: 978-1424427086, Mason, S.J., pp. 1867-1872, Winter Simulation Conference 2008, Miami

Jodlbauer, H. (2008). Produktionsoptimierung: Wertschaffende sowie kundenorientierte Planung und Steuerung, Springer, ISBN: 978-3211781401, Vienna

Marek, R.P.; Elkins, D.A. \& Smith, D.R. (2001). Understanding the Fundamentals of Kanban and CONWIP Pull Systems using Simulation, Proceedings of the 2001 Winter Simulation Conference, Arlington, VA, USA, ISBN: 978-0780373075, Peters, B.A., pp. 921-929, IEEE Computer Society, Washington

Olhager, J. (2003). Strategic Positioning of the Order Penetration Point. International Journal of Production Economics, Vol. 85, No. 3, (September 2003) pp. 319-329, ISSN: 0925-5273

Spearman, M.L.; Woodruff, D.L. \& Hopp, W.J. (1990). CONWIP: a Pull Alternative to Kanban. International Journal of Production Research, Vol. 28, No. 5, (May 1990) pp. 879-894, ISSN: 0020-7543 